\title{
Anthropometric Correlates of Human Anger
}

Running headline: Anthropometric Correlates of Anger

\author{
Michael E. Price, Department of Psychology, Brunel University \\ James Dunn, Department of Psychology, Brunel University \\ Sian Hopkins, Department of Psychology, Brunel University \\ Jinsheng Kang, School of Engineering and Design, Brunel University
}

Correspondence concerning this article should be addressed to:

Michael E. Price

Department of Psychology

School of Social Sciences

Brunel University

Uxbridge, Middlesex

UB8 3PH

United Kingdom

E-mail: michael.price@brunel.ac.uk

WORD COUNT (includes abstract, main text and references): 5,469 
1 Abstract

2

3 The recalibrational theory of human anger predicts positive correlations between aggressive

4 formidability and anger levels in males, and between physical attractiveness and anger levels

5 in females. We tested these predictions by using a three dimensional body scanner to collect

6 anthropometric data about male aggressive formidability (measures of upper body

7 muscularity and leg-body ratio) and female bodily attractiveness (waist-hip ratio, body mass

8 index, overall body shape femininity, and several other measures). Predictions were partially

9 supported: in males, two of three anger measures correlated significantly positively with

several muscularity measures; in females, self-perceived attractiveness correlated

11 significantly positively with two anger measures. However, most of these significant results were observed only after excluding from the sample 27 participants who were older than undergraduate age, leaving a subsample of 40 males and 51 females. Evidence for relationships between anthropometric attractiveness indicators and anger measures was weak, but there was some evidence for relationships between anthropometric attractiveness

16 indicators and self-perceived attractiveness measures. While our results support the recalibrational theory's prediction that anger usage and formidability are positively correlated

18 in males, and suggest that this formidability can be assessed via anthropometric measures

19 alone, they also suggest that this prediction may not apply to populations older than undergraduate age. Further, our results suggest that while female anger levels relate

21 positively to self-perceived attractiveness, they are unrelated to most anthropometric

22 measures of bodily attractiveness.

23 Keywords: recalibrational theory; anger; aggression; self-perceived physical attractiveness;

24 muscularity; evolutionary psychology 
27

28

29

30

31

32

33

34

35

\section{Introduction}

According to the recalibrational theory of anger (Sell et al., 2009), the human psychological program that generates anger evolved to incentivize others to recalibrate upwards their valuation of the angry individual's welfare. Ancestral individuals used anger to convince others to treat them better, and the more power they had to harm and/or benefit others, the more convincing they would have been in this regard: "anger is more likely to be triggered when an actor is positioned to make the price of resisting recalibration high. This price is higher when the actor's formidability (ability to inflict costs on the target) or the actor's ability to confer/withhold benefits is greater" (Sell et al., 2009: 15074).

The recalibrational theory predicts that certain traits would have been particularly important influences in ancestral environments on an individual's ability to impose costs or confer benefits. One of these influences, aggressive formidability, would have enhanced the ability to inflict costs. Because selection for traits promoting success in physical conflict is stronger in males than in females (Trivers, 1972), traits that enhance aggressive formidability (e.g., upper body muscle mass) should be more important as aspects of cost-imposition ability in males than in females. Another important influence on one's ability to impose costs/confer benefits is physical attractiveness, which, as an indicator of health and mate value in both sexes, would have enhanced the ability to confer benefits as an ally or mate. Attractiveness would have probably been a more significant aspect of benefit-conferral ability in females than in males, because it is relatively more important in females as an index of both fertility and mate value (Grammer et al., 2003). It should also be noted that some traits may enhance abilities to both inflict costs and confer benefits. For example, although Sell et al. focus on how strength could be used to impose costs, strength could also be used to provide benefits such as protection from crime (Snyder et al., 2011). Further, moderately high male upper 
51 body muscularity is itself perceived as attractive by females (Frederick \& Haselton, 2007),

52 which may help explain why men who are more muscular report having had more sex

53 partners (Frederick \& Haselton, 2007; Lassek \& Gaulin, 2009).

54 Support for the predictions of the recalibrational theory is provided by Sell et al.

55 (2009), who found significant positive correlations in males, but not in females, between

56 upper body strength and the likelihoods of getting angry, of getting into physical fights, of

57 believing in the utility of personal and political aggression, and of succeeding in conflict. (A

58 related finding is that women perceive men with more muscular bodies as being more

59 "volatile" [Frederick \& Haselton, 2007]). Sell et al. also found significant positive

60 correlations in females between self-perceived physical attractiveness and all of these anger

61 measures, with the exception of likelihood of getting into physical fights. The correlations

62 between attractiveness and anger measures were weaker in males, and most of these zero-

63 order correlations became marginal or non-significant after controlling for the effects of

64 strength.

Previous research suggests, then, that there are significant sex differences in the traits

66 associated with anger-related outcome variables: upper body strength is important in males

67 but unimportant in females, whereas self-assessed physical attractiveness is relatively more

68 important in females than in males. The main purpose of the current study was to test these

69 predictions using predictor variables that were based on anthropometric data, as opposed to

70 the kinds of data (mainly strength tests and self-report) collected in prior research. Sell et al.

71 (2009) assessed male aggressive formidability via several measures of strength: weight-lifting

72 ability, self-perceived strength, strength as perceived by others, flexed bicep circumference,

73 and strength scores as recorded by a hand dynamometer. Their only anthropometric measure,

74 flexed bicep circumference, was included as one item in a four-item composite variable, so 
75

they did not investigate the extent to which male anger measures could be predicted based on anthropometric variables alone, which is an issue that we examined in depth.

Further, Sell et al. used a measure of attractiveness that was based on self-report data, rather than on any anthropometric data that would be informative about bodily attractiveness.

Because they did not collect this kind of anthropometric data, they could not test the hypotheses that females with more attractive bodies (as assessed anthropometrically) tend to use anger more, and that self-perceived attractiveness accurately reflects anthropometricallymeasured attractiveness. Both of these hypotheses are relevant to the recalibrational theory, because this theory assumes that attractive people (especially, females) have greater power to confer benefits because other people think they are attractive. While Sell et al. are correct that human ancestors needed to perceive their own attractiveness in order to assess the extent to which they could leverage it to their own advantage, it is also true that their perceptions needed to have been rooted in reality in order to be used adaptively (otherwise, they would have miscalculated the actual extent of their benefit-conferral advantage, and would thus have used anger either less or more frequently than would have been optimal for them). However, good evidence for a positive relationship between anthropometrically-measured attractiveness and female anger levels has apparently not yet been produced, and some evidence suggests that there is no relationship between self-perceived attractiveness and anthropometric attractiveness in females (Brewer et al., 2007). We tested for both of these types of relationships.

We used two kinds of variables as indicators of male formidability. First, as explained above, we predicted that measures of upper-body muscularity such as chest, shoulder and bicep circumference would correlate positively with anger use in males. Second, we expected leg-body ratio (LBR) to correlate negatively with anger use in males. LBR appears to correlate inversely with male fighting ability in a variety of primate species, 
100 perhaps because males with lower LBR are harder to knock down (Carrier, 2006), and/or 101 because as a sexually dimorphic trait (Brown et al., 2008), LBR is associated with other 102 testosterone-dependent traits that influence formidability.

103 We used a variety of variables as indicators of female attractiveness. First, we 104 predicted that LBR would relate positively to anger in females: LBR appears to be associated 105 positively with body-shape femininity and attractiveness in females (Brown et al., 2008; 106 Rilling et al., 2009; Swami et al., 2006), although some research suggests that a moderate 107 LBR is most attractive in females (Frederick et al., 2010; Swami et al., 2007). Second, a 108 lower female waist-hip ratio (WHR) is regarded as more attractive by males in a wide variety 109 of cultures (Singh, 1993, 2002), so we expected WHR to relate negatively to anger in 110 females. (However, some evidence suggests cross-cultural variation in WHR preferences; for 111 reviews see Sugiyama [2005] and Swami \& Salem [2011]). Third, waist circumference was

112 found by Rilling et al. (2009) to be a particularly significant inverse correlate of female 113 attractiveness, so we predicted it would relate negatively to female anger. Fourth and fifth, 114 we predicted that body mass index (BMI) and volume height index (VHI) would relate 115 negatively to female anger: Tovee et al. (2002) emphasized the importance of BMI as a 116 predictor of female attractiveness, while Fan et al. (2004) found VHI to be a better predictor.

117 Sixth, we predicted that bust-underbust ratio (BUR) would relate positively to female 118 attractiveness, based on work by Brown et al. (2008) which identified this relationship.

119 Finally, because a more sex-typical (i.e., feminine) female body shape is regarded as more 120 attractive (Brown et al., 2008), we derived a measure of overall "body shape femininity" 121 using principal component analysis and predicted that it would associate positively with 122 female anger. 
125

126

127

128

129

130

131

132

133

134

135

136

137

138

139

140

141

142

143

144

145

146

147

148

can then use to extract hundreds of accurate measurements. According to the manufacturer, the scanner's point accuracy is $<1 \mathrm{~mm}$, and its circumferential accuracy is $<3 \mathrm{~mm}\left(\mathrm{TC}^{2}\right.$, 2010).

\section{Method}

\subsection{Participants and procedure}

One-hundred and eighteen participants (56 males, 62 females, mean age $21.95 \pm 4.53$ years), mostly undergraduates at an English University, participated in exchange for participation pool credit and/or a copy of their 3D body scan (for reasons discussed below, this sample size was ultimately reduced to 91). After completing the questionnaire portion of the study, participants' height to top of head and weight were recorded by stadiometer and digital scale. Using methods similar to those used by Brown et al. (2008), participants were then body-scanned with an NX12 scanner, manufactured by TC ${ }^{2}$ (Cary, North Carolina, USA). During the scan, participants wore scanner-appropriate clothing (tight-fitting briefs and for females, a sports bra), and stood erect in a standardized pose, without flexing any muscles, with arms straightened and held slightly away from the sides of the body. Two high-quality scans were obtained from each participant, and the 23 trait measurements used in this study were extracted from each scan. The two measurements of each trait were first used to assess repeatabilities, and were then averaged to produce the single measurement used to generate predictor variables. Complete scans were obtained for all participants, with the exception of two very dark-skinned males whose scans were incomplete below the elbow (the NX12 sometimes has difficulty scanning very dark skin). These participants were excluded from analyses that required the missing data. 


\subsection{Predictor variables}

With the exception of height and weight (described above), all other anthropometric measurements were extracted, in centimeters, by the NX12 scanner. The following measurements were used to assess upper body muscularity: horizontal shoulder circumference, left and right vertical shoulder circumference (measured from the underarm to the top of the shoulder), chest circumference, left and right bicep circumference, left and right elbow circumference, left and right forearm circumference, and left and right wrist circumference. In order to produce a general measure of upper body muscularity, we created a composite measure out of the most important components of upper body muscle mass: we summed the $z$-scores of horizontal shoulder circumference, chest circumference, and mean bicep circumference, and called it "upper body size". In addition, so that we could compare the effects of upper and lower body muscularity, we extracted measurements of left and right thigh circumference and left and right calf circumference. To measure waist circumference, we took the minimum circumference between the lower ribs and top of pelvis, and to measure hip circumference we took the widest circumference between crotch and waist. We determined WHR by dividing waist circumference by hip circumference. We calculated BMI by dividing weight in kilograms by the square of height (to top of head) in meters, and VHI by dividing body volume by the square of height (to top of head) in meters. To calculate BUR, we divided bust circumference by underbust circumference. Finally, to determine LBR, we measured circumference at the base of the lower torso, passing through the small of the lower back, and divided the frontal height of this circumference by height (to top of head). Repeatabilities (intraclass correlation coefficients) for all trait measurements extracted by the NX12 were high, ranging from .893 to .999 .

To create the overall body shape femininity variable, our technique was similar to that described in Brown et al. (2008). First, independent $t$-tests were conducted on a variety of 
175 traits known to be sexually dimorphic, in order to see which traits would be associated with

176 the greatest between-sex variation. The four traits which generated the largest $t$ values were

177 WHR $(t=11.44)$, horizontal shoulder circumference $(t=10.97)$, BUR $(t=-9.63)$, and LBR

$178(t=-9.14)$. Next, a principal component analysis on these four traits produced one

179 component with an eigenvalue of 2.56 (the only eigenvalue greater than 1.00 ), which

180 accounted for $63.98 \%$ of the total variance. Variable loadings (WHR $=.89$, horizontal

181 shoulder circumference $=.81, \mathrm{BUR}=-.74, \mathrm{LBR}=-.76)$ indicated that this component

182 captured body shape sex typicality such that higher values indicated a more masculine shape,

183 and lower values indicated a more feminine shape. We reverse coded this component so that

184 we could label it "body shape femininity".

185 Finally, so that we could examine the relationship between bodily and self-perceived

186 attractiveness, we measured three kinds of self-perceived attractiveness via three different

187 items. With two of these items, male and female participants responded on a nine-point scale 188 ranging from "Very unattractive" to "Very attractive" to the following items: "Please tick the

189 box indicating how physically attractive you think you are, in general” (“S-P attract

190 [general]"), and "Please tick the box indicating how physically attractive you think your body

191 is" ("S-P attract [body]"). All participants provided responses to both of these items, with the

192 exception of three males who responded to neither. The third item, administered to female

193 participants only, was the measure of self-perceived attractiveness used by Sell et al. (2009):

194 "Please fill in the blank: "I am more attractive than __ \% of other women" ("S-P attract 195 [percentile]").

196

197

\subsection{Outcome variables}

198

Our three anger-related outcome variables were composed of items used in the

199 original measures designed by Sell et al. (2009). Participants responded to all items on a 9- 
200 point scale from "Strongly disagree" to "Strongly agree". First, our "proneness to anger" 201 measure, which assesses one's general likelihood to become angry in everyday life, was the 202 mean response to items 3, 6, 7, 12, 15, 18 and 21 of the original measure (Cronbach's $\alpha=$ 203 .75). Sample items are "People often irritate me" and "It is harder to get me angry than other 204 205 206 included in analyses involving these variables.

\section{Results}

\subsection{Exclusion of older participants}

The initial analysis indicated that while few of the kinds of effects reported by Sell et al. (2009) could be observed when analyzing the entire 118-participant sample, many of them could be observed among the undergraduate-aged participants only. The age structure of our sample differed from that of the samples used by Sell et al., in that we had a larger percentage

222 of participants who were older than undergraduate age, which gave our sample a higher age 
$225 \pm 1.24$ (females, sample two) (A. Sell, personal communication, May 25, 2010). Figures for

226 our original sample were $21.95 \pm 4.53$, but by excluding all participants who were older than

227 the typical undergraduate age range of 18-23 years, we reduced these figures to $19.93 \pm 1.44$,

228 which were more in line with the Sell at al. samples. Excluding the 27 participants who were

229 older than 23 years reduced our sample size to 91 ( 51 females, 40 males). The below

230 analysis was conducted on this undergraduate-aged subsample only.

231

232

\subsection{Formidability-anger correlations}

233

Table 1 presents descriptive statistics for all study variables, separately by sex, as well

234

235

236

237

238

239

240

241

242

243

244

245

246

247

248

as the results of $t$-tests that reveal whether each trait displayed significant sexual dimorphism.

Table 2 presents the sex-specific correlations between each predictor variable and each

outcome variable. Results in Table 2 show that as predicted, measures of upper body

muscularity correlated significantly positively with proneness to anger and political

aggression in males. Four distinct upper body traits (not including the composite variable,

upper body size) correlated significantly positively with both of these anger variables in

males: horizontal shoulder circumference, mean vertical shoulder circumference, chest

circumference, and mean bicep circumference. Overall, the anger measure that correlated

most strongly positively with the upper body muscularity measures was proneness to anger.

Surprisingly, none of these upper body muscularity measures correlated significantly

positively with history of fighting, although most of these correlations were positive and

several approached significance. As expected, no significant correlations occurred between

upper body muscularity measures and anger measures among females. Also as expected,

lower body muscularity measures were relatively weak predictors of anger measures in

males, compared to upper body muscularity measures: the only significant positive 
249

250

251

252

253

254

255

256

257

258

259

260

261

262

265

266

267

268

269

270

271

272

correlation between a lower body muscularity trait and an anger measure was between mean calf circumference and political aggression in males.

The predicted negative correlations between LBR and anger measures in males were not significant, although in the case of proneness to anger this correlation was marginally significant $(p=.065)$. Because LBR and upper body size were both highly correlated with proneness to anger in males, but not with each other (the correlation between upper body size and LBR in males was $r=-.14, p=.189)$, the independent effects of these two predictors on male proneness to anger were investigated via a multiple regression model. Upper body size and LBR were entered together into this model with male proneness to anger as the outcome variable. The overall model was significant $\left(R^{2}=.22, p=.005\right)$, but only upper body size $(\beta$ $=.40, p=.005)$, and not $\operatorname{LBR}(\beta=-.19, p=.106)$, explained significant unique variance in male proneness to anger.

\subsection{Attractiveness-anger correlations}

In females, the only significant correlations between any of the seven anthropometric attractiveness measures and any of the three anger measures were between LBR and proneness to anger (in the expected positive direction) and between WHR and political aggression (in the expected negative direction). The only other indexes of attractiveness that did correlate significantly with any anger measure in females were two non-anthropometric ones, S-P attract [body], which correlated significantly positively with political aggression, and S-P attract [percentile], which correlated significantly positively with both proneness to anger and political aggression. 
The three self-perceived attractiveness measures varied in the extent to which they

274

275

276

277 278 related to the female anthropometric attractiveness measures. As Table 3 shows, while S-P attract [general] and S-P attract [percentile] correlated significantly in the expected direction with only one of the seven anthropometric attractiveness measures (body shape femininity), S-P attract [body] performed relatively well, correlating significantly in the expected direction with six of these seven measures.

The one anthropometric attractiveness measure which failed to correlate significantly in the expected direction with any self-perceived attractiveness measure in females was LBR. Although the one-tailed correlations between LBR and S-P attract [body] were significant among both males and females, in neither case was this correlation in the expected direction or significant as a two-tailed correlation. Excessive speculation about the reasons for these correlations is thus not warranted. However, we should note that in the female case, the correlation is due to LBR relating positively to body fat measures (WC, WHR, BMI and VHI) which themselves relate negatively to S-P attract [body].

\section{Discussion}

Two types of predictions of the recalibrational theory of anger (Sell et al., 2009) were supported in the current study. First, we found that indicators of aggressive formidability were significantly positively related to proneness to anger and political aggression in males. While Sell at al. used predictors based mainly on upper body strength to reveal these relationships, we used only anthropometric predictors (especially measures of upper body muscularity). Second, we replicated the findings that among females, self-perceived physical attractiveness is significantly positively correlated with proneness to anger and political aggression. We did not find indicators of aggressive formidability to be significantly 
298 positively correlated with history of fighting in males, but some of these correlations were 299 close to significantly positive.

Other findings from our study suggest that the predictions of the recalibrational theory 301 should be accompanied by some important caveats. First, most of our significant results were 302 significant only among the younger participants in our sample. This was especially true with 303 the correlations between muscularity and anger usage in males. Among the 40 males that 304 were included in the younger subsample (i.e., the male participants analyzed in the above 305 results section), there were a total of 12 significantly positive correlations found between the 306 eight upper body muscularity traits and the three anger measures (Table 2), but when the full 56-male sample was analyzed, only two such correlations were found. The correlations between self-perceived attractiveness and anger measures in females held up comparatively 309 well in the full sample: of the three positive correlations between the self-perceived attractiveness and anger measures that were significant among the 51 females in the younger subsample, two were also significant in the full 62-female sample (the exception was the correlation between S-P attract [percentile] and proneness to anger). Our lack of full-sample results does not contrast with any findings from Sell et al., because our younger subsample was more closely matched, compared to our full sample, with their samples. However, this lack does suggest that the predictions of the recalibrational 316 theory - especially, that of a positive relationship between aggressive formidability and anger 317 in males - might apply best to populations of undergraduate age. Male aggression tends to 318 peak around the undergraduate-age years and to decline thereafter (Daly \& Wilson, 1988), and in our full male sample $(n=56)$, age was significantly negatively correlated with political 320 aggression $(r=-.30, p=.014)$, and nearly so with proneness to anger and history of fighting 321 (both $r$ 's $=-.21$, both $p$ 's $=.06$ ). It may be that as anger levels fade with age, so does the 322 relationship between muscularity and anger. Testosterone levels probably affect some of this 
323 study's most important sexually dimorphic variables (e.g., muscularity, proneness to anger),

324

325

and as age advances further past the pubertal stages when most sexual differentiation occurs, associations between these variables may weaken. Further, as males age beyond their undergraduate years, their formidability may become more dependent on social power and achievement (e.g., on having a high income or an influential role in their organization) as opposed to physique and strength, which may also contribute to the weakening of the muscularity-anger correlation.

The second caveat is that although the recalibrational theory predicts a positive correlation between female attractiveness and anger usage, this prediction may not be accurate if attractiveness is assessed in terms of standard anthropometric measures of bodily attractiveness. Of the seven such anthropometric predictors that we looked at, leg-body ratio and waist-hip ratio were the only two that correlated significantly with any of the three anger measures in females, and each predictor did so with only one anger measure. The recalibrational theory does predict that the effect of 'objective' (other-perceived) attractiveness on anger usage will be mediated by self-perceived attractiveness, so perhaps anthropometric attractiveness influences anger only indirectly. This argument receives some support from the fact that some self-perceived attractiveness measures correlated significantly positively both with some anger measures, and with some anthropometric attractiveness measures, in females. On the other hand, the self-perceived attractiveness measure that best predicted female anger, S-P attract [percentile] - which was also the self-perceived attractiveness measure used in Sell et al. (2009) - correlated significantly with only one of the seven anthropometric predicators of attractiveness (body shape femininity). Another selfperceived attractiveness measure, S-P attract [body], performed much better as a predictor of anthropometric attractiveness by correlating significantly in the expected direction with six of 
347 the seven anthropometric predicators; however, it performed worse than S-P attract

348 [percentile] as a predictor of female anger usage.

The lack of strong correlations between anthropometric attractiveness measures and

350 female anger measures, and the lack of strong evidence that the measures of self-perceived

351 attractiveness that best predict anthropometric attractiveness are the same ones that best

352 predict female anger usage, raise a question: if females modulate their anger usage based on

353 their self-perceived attractiveness, then what information are they using to assess their own

354 attractiveness? Perhaps their assessments are based on facial attractiveness, which is an

355 important element of overall physical attractiveness that the current study did not measure.

356 However, it is possible that anger is modulated based on self-perceived attractiveness

357 assessments that are largely inaccurate. Previous research suggests that people are poor to

358 moderately good assessors of their own attractiveness (Brewer et al., 2007; Marcus \& Miller,

359 2003; Mulford et al., 1998). In a study that was relatively similar to the current one in terms

360 of variables examined, females' self-perceived attractiveness ratings did not correlate

361 significantly with anthropometric measures of their bodily attractiveness (WHR, BMI) or

362 with other people's ratings of their facial attractiveness (Brewer et al., 2007). The authors of

363 that study explained this inaccuracy by noting that their female participants, particularly the

364 most attractive ones, tended to overestimate their own attractiveness, perhaps as the result of

365 adaptive self-deception (Trivers, 1999). However it is not clear that female participants in the

366 current study were overestimating their own physical attractiveness; in fact, as our average

367 female participant stated that she was more attractive than only about $41 \%$ of other women

368 (i.e., the mean of S-P attract [percentile] was 41.39), it is plausible that they tended to err on

369 the side of humility. Moreover, we found that when female participants were asked

370 specifically about their self-perceived bodily attractiveness (S-P attract [body]), their

371 perceptions became reasonably accurate (although as noted, S-P attract [body] was not the 
372 self-perceived attractiveness measure that best predicted female anger usage). The lack of

373 relationships in females between anthropometric attractiveness measures and anger, and

374 between anthropometric attractiveness measures and the self-perceived attractiveness

375 measures that best predict anger, are puzzles meriting further investigation.

In addition to these caveats, some study limitations bear mentioning. First, we (like

377 Sell et al.) have been interpreting correlations between formidability and anger as evidence

378 that formidability causes anger. However, anger could also lead to formidability, if anger-

379 prone men spent more time working out in the gym. Either of these causal relationships

380 would be consistent with the correlations we found, and if both existed, there could be a

381 recursive relationship between formidability and anger: as anger-prone people became

382 stronger, they would become even more anger-prone. A second limitation is that our sample

383 size was relatively small, due both to time constraints imposed by our use of the body

384 scanner, and to our reliance on an age-restricted subsample. With a larger sample, some

385 observed non-significant relationships (such as those between history of fighting and

386 muscularity in males) would likely have been significant.

387 In conclusion, our results provide support for the recalibrational theory's predictions

388 that aggressive formidability will correlate positively with male anger usage, and that self-

389 perceived attractiveness will correlate positively with female anger usage, with the caveat

390 that these correlations may be stronger in populations of undergraduate age. Further, our

391 results suggest that the relationship between aggressive formidability and anger in males can

392 be observed even when formidability is assessed only via anthropometric measurements. Our

393 results also suggest that while anger usage correlates positively with female self-perceived

394 attractiveness, it in general does not do so with relatively objective measures of female bodily

395 attractiveness. While females may be basing their anger usage on their perceptions of their 
398

399

400

401

402

403

404

405

406

407

408

409

410

411

412

413

414

415

416

417

418

419

420

own attractiveness, their perceptions do not seem to be related in a straightforward way to information about their attractiveness as assessed anthropometrically.

\section{Acknowledgements}

We gratefully acknowledge the contributions of Orsolya Zsofia Bote and three anonymous reviewers.

\section{References}

Brewer, G., Archer, J. \& Manning, J. (2007). Physical attractiveness: The objective ornament and subjective self-ratings. Journal of Evolutionary Psychology, 5, 29-38.

Brown, W.M., Price, M.E., Kang, J., Pound, N., Zhao, Y., \& Yu, H. (2008). Fluctuating asymmetry and preferences for sex-typical bodily characteristics. Proceedings of the National Academy of Sciences, USA, 105, 12938-12943.

Carrier, D. R. (2006). The short legs of great apes: Evidence for aggressive behavior in australopiths. Evolution (Lawrence, Kans), 61, 596-605.

Daly, M. \& Wilson, M. (1988). Homicide. Hawthorne, NY: Aldine de Gruyter.

Fan, J., Liu, F. Wu, J. \& Dai, W. (2004). Visual perception of female physical attractiveness. Proceedings of the Royal Society B: Biological Sciences, 271, 347-352.

Frederick, D. A. \& Haselton, M. G. (2007). Why is muscularity sexy? Tests of the fitness indicator hypothesis. Personality and Social Psychology Bulletin, 33, 1167-1183.

Frederick, D. A., Hadji-Michael, M., Funham, A., \& Swami, V. (2010). The influence of legto-body ratio (LBR) on judgments of female physical attractiveness: Assessments of computer-generated images varying in LBR. Body Image, 7, 51-55.

Grammer, K., Fink, B., Møller, A.P., \& Thornhill, R. (2003). Darwinian aesthetics: Sexual 
421

422

423

424

425

426

427

428

429

430

431

432

433

434

435

436

437

438

439

440

441

442

443

444

445

selection and the biology of beauty. Biological Reviews, 78, 385-407.

Lassek, W. D., \& Gaulin, S. J. C. (2009). Costs and benefits of fat-free muscle mass in men: Relationship to mating success, dietary requirements and native immunity. Evolution and Human Behavior, 30, 322-328.

Marcus, D. K. \& Miller, R. S. (2003). Sex differences in judgments of physical attractiveness: A social relations analysis. Personality and Social Psychology Bulletin, $29,325-335$.

Mulford, M., Orbell, J., Shatto, C., \& Stockard, J. (1998). Physical attractiveness, opportunity, and success in everyday exchange. American Journal of Sociology, 103, $1565-1592$.

Rilling, J. K., Kaufman, T. L., Smith, E. O., Patel, R., \& Worthman, C. M. (2009).

Abdominal depth and waist circumference as influential determinants of human female attractiveness. Evolution and Human Behavior, 30, 21-31.

Sell, A., Tooby, J., \& Cosmides, L. (2009). Formidability and the logic of human anger. Proceedings of the National Academy of Sciences, USA, 106, 15073-15078.

Singh, D. (1993). Adaptive significance of female physical attractiveness: Role of waist-tohip ratio. Journal of Personality and Social Psychology, 65, 292-307.

Singh, D. (2002). Female mate value at a glance: Relationship of waist to hip ratio to health, fecundity and attractiveness. Neuroendocrinology Letters, 23(Suppl 4), 81-91.

Snyder, J. K., Fessler, D. M. T., Tiokhin, L., Frederick, D. A., Lee, S. W. \& Navarrete, C. D. (2011). Trade-offs in a dangerous world: women's fear of crime predicts preferences for aggressive and formidable mates. Evolution and Human Behavior, 32, 127-137.

Sugiyama, L. S. (2005). Physical attractiveness in adaptationist perspective. In D. M. Buss (Ed.), The handbook of evolutionary psychology (pp. 293-343). New York: John Wiley \& Sons, Ltd. 
446 Swami, V., Einon, D., \& Furnham, A. (2006). An investigation of the leg-to-body ratio as a 447 human aesthetic criterion. Body Image, 3, 317-323.

448 Swami, V., Einon, D., \& Furnham, A. (2007). Cultural significance of leg-to-body ratio 449 450 preferences? Evidence from Britain and rural Malaysia. Asian Journal of Social Psychology, 10, 265-269.

451

452

453

454

455

456

457

458

459

460

461

462
(Ed.), Evolutionary psychology: A critical introduction (pp. 131-181). West Sussex:

Wiley/BPS Blackwell

$\mathrm{TC}^{2}$ (2010). Information about scanner accuracy downloaded from http://www.tc2.com/index_3dbodyscan.html on 24 November 2010.

Tovee, M. J., Hancock, P. J. B., Mahmoodi, S., Singleton, B. R. R., \& Cornelissen, P. L. (2002). Human female attractiveness: Waveform analysis of body shape. Proceedings of the Royal Society B: Biological Sciences, 266, 2205-2213.

Trivers, R.L. (1972). Parental investment and sexual selection. In B. Campbell (Ed.), Sexual selection and the descent of man, 1871-1971 (pp. 136-179). Chicago, IL: Aldine.

Trivers, R.L. (1999). The elements of a scientific theory of self-deception. New York Academy of Sciences, 187, 111-126. 
Table 1

Descriptive statistics of all study variables, with results of t-tests for sex differences

\begin{tabular}{|c|c|c|c|c|c|c|c|c|}
\hline \multirow[b]{2}{*}{ Variable } & \multicolumn{3}{|c|}{ Males } & \multicolumn{3}{|c|}{ Females } & \multicolumn{2}{|c|}{ Sex difference } \\
\hline & $n$ & Mean & S.D. & $n$ & Mean & S.D. & $t$ & $p$ \\
\hline Horiz. shoulder circ. $(\mathrm{cm})$ & 40 & 111.98 & 4.83 & 51 & 101.41 & 5.31 & 9.81 & $<.001$ \\
\hline Vert. shoulder circ. $(\mathrm{cm})$ & 40 & 44.20 & 2.35 & 51 & 39.57 & 3.59 & 7.05 & $<.001$ \\
\hline Chest circumference $(\mathrm{cm})$ & 40 & 101.61 & 6.08 & 51 & 91.65 & 6.58 & 7.42 & $<.001$ \\
\hline Bicep circumference $(\mathrm{cm})$ & 40 & 30.44 & 2.63 & 51 & 27.75 & 3.36 & 4.15 & $<.001$ \\
\hline Elbow circumference $(\mathrm{cm})$ & 39 & 26.48 & 1.43 & 51 & 24.54 & 2.21 & 4.79 & $<.001$ \\
\hline Forearm circ. $(\mathrm{cm})$ & 39 & 27.06 & 1.59 & 51 & 24.68 & 2.01 & 6.06 & $<.001$ \\
\hline Wrist circumference $(\mathrm{cm})$ & 39 & 17.84 & 0.82 & 51 & 16.86 & 0.81 & 5.70 & $<.001$ \\
\hline Upper body size & 40 & 1.63 & 2.05 & 51 & -1.80 & 2.38 & 7.23 & $<.001$ \\
\hline Thigh circumference $(\mathrm{cm})$ & 40 & 54.84 & 4.10 & 51 & 57.10 & 6.65 & -1.89 & .063 \\
\hline Calf circumference $(\mathrm{cm})$ & 40 & 36.50 & 2.35 & 51 & 35.45 & 3.35 & 1.69 & .096 \\
\hline Leg to body ratio & 40 & 0.58 & 0.03 & 51 & 0.62 & 0.02 & -7.65 & $<.001$ \\
\hline Waist circumference $(\mathrm{cm})$ & 40 & 78.88 & 7.12 & 51 & 71.93 & 8.18 & 4.25 & $<.001$ \\
\hline Waist to hip ratio & 40 & 0.80 & 0.04 & 51 & 0.71 & 0.05 & 9.77 & $<.001$ \\
\hline Body mass index & 40 & 22.86 & 2.59 & 51 & 22.29 & 3.60 & 0.85 & .400 \\
\hline Volume-height index & 40 & 20.63 & 2.61 & 51 & 20.51 & 3.37 & 0.19 & .852 \\
\hline Bust to underbust ratio & 40 & 1.11 & 0.03 & 51 & 1.19 & 0.07 & -7.47 & $<.001$ \\
\hline Body shape femininity & 40 & -0.83 & 0.55 & 51 & 0.83 & 0.44 & -16.12 & $<.001$ \\
\hline S-P attract [general] & 38 & 6.08 & 0.91 & 51 & 5.92 & 1.02 & 0.75 & .453 \\
\hline S-P attract [body] & 38 & 5.87 & 1.34 & 51 & 5.43 & 1.60 & 1.36 & .176 \\
\hline S-P attract [percentile] & - & - & - & 51 & 41.39 & 15.90 & - & - \\
\hline Proneness to anger & 40 & 5.29 & 1.19 & 51 & 5.27 & 1.33 & 0.06 & .951 \\
\hline History of fighting & 39 & 4.96 & 2.26 & 51 & 3.60 & 1.92 & 3.10 & .003 \\
\hline Political aggression & 39 & 4.15 & 1.54 & 51 & 3.25 & 1.28 & 3.04 & .003 \\
\hline
\end{tabular}


Table 2

Correlations between predictors and anger measures

\begin{tabular}{|c|c|c|c|c|c|c|}
\hline \multirow[b]{2}{*}{ Trait } & \multicolumn{2}{|c|}{ Proneness to anger } & \multicolumn{2}{|c|}{ History of fighting } & \multicolumn{2}{|c|}{ Political aggression } \\
\hline & Male $r$ & Female $r$ & Male $r$ & Female $r$ & Male $r$ & Female $r$ \\
\hline Horizontal shoulder circ. & $.41^{* *}$ & .01 & .24 & .09 & $.31 *$ & -.18 \\
\hline Vertical shoulder circ. & $.35^{*}$ & .03 & .22 & .08 & $.28^{*}$ & .01 \\
\hline Chest circumference & $.42 * *$ & -.06 & .18 & .20 & $.32 *$ & -.14 \\
\hline Bicep circumference & $.39 * *$ & .04 & .21 & .23 & $.34 *$ & -.12 \\
\hline Elbow circumference & $.43^{* *}$ & .01 & .06 & .12 & .15 & -.08 \\
\hline Forearm circumference & $.37 * *$ & .02 & .09 & .16 & .21 & -.08 \\
\hline Wrist circumference & .26 & -.07 & -.03 & .11 & .04 & -.15 \\
\hline Upper body size & $.43 * *$ & $<-.01$ & .22 & .19 & $.34 *$ & -.15 \\
\hline Thigh circumference & .11 & -.04 & .16 & .14 & .23 & -.15 \\
\hline Calf circumference & .05 & -.08 & -.02 & .14 & $.27^{*}$ & -.15 \\
\hline Leg to body ratio & -.24 & $.31 *$ & -.13 & .19 & -.04 & -.13 \\
\hline Waist circumference & .20 & .03 & -.08 & .05 & .23 & -.22 \\
\hline Waist to hip ratio & .13 & .18 & -.21 & .05 & .13 & $-.28 *$ \\
\hline Body mass index & .21 & -.02 & -.02 & .13 & .26 & -.16 \\
\hline Volume-height index & $.31^{*}$ & $<-.01$ & .07 & .14 & .24 & -.18 \\
\hline Bust to underbust ratio & -.01 & -.02 & $.27 *$ & -.02 & .05 & -.01 \\
\hline Body shape femininity & $-.33 *$ & .02 & $<-.01$ & -.01 & -.18 & .19 \\
\hline S-P attract [general] & .22 & .20 & .05 & -.09 & .03 & .11 \\
\hline S-P attract [body] & .19 & .08 & .19 & -.18 & .10 & $.27^{*}$ \\
\hline S-P attract [percentile] & - & $.26^{*}$ & - & -.12 & - & $.29 *$ \\
\hline
\end{tabular}

Note. Results are for the university-aged subsample only (ages 18-23, 40 males, 51 females). Values of $p$ are one-tailed. For bilateral traits the mean of left-right measurements are presented.

${ }^{*} p<.05, * * p<.01$. 
Table 3

Intercorrelations between attractiveness measures

\begin{tabular}{|c|c|c|c|c|c|c|c|c|c|}
\hline Measure & 1 & 2 & 3 & 4 & 5 & 6 & 7 & 8 & 9 \\
\hline 1. LBR & - & $-.32 *$ & -.26 & $-.41 * *$ & -.24 & .18 & $.67 * * *$ & .08 & $.30 *$ \\
\hline 2. $\mathrm{WC}$ & $.41 * *$ & - & $.84 * * *$ & $.83 * * *$ & $.88 * * *$ & $-.34 *$ & $-.78 * * *$ & -.06 & -.16 \\
\hline 3. WHR & $.28 *$ & $.75 * * *$ & - & $.66 * * *$ & $.62 * * *$ & $-.50 * *$ & $-.79 * * *$ & .05 & -.02 \\
\hline 4. BMI & $.34 * *$ & $.89 * * *$ & $.55 * * *$ & - & $.84 * * *$ & $-.37 *$ & $-.80 * * *$ & -.05 & -.11 \\
\hline 5. VHI & $.37 * *$ & $.90 * * *$ & $.56 * * *$ & $.98 * * *$ & - & -.18 & $-.66 * * *$ & -.15 & -.18 \\
\hline 6. BUR & .12 & .22 & .05 & $.36 * *$ & $.28 *$ & - & $.56 * * *$ & -.14 & -.13 \\
\hline 7. $\mathrm{BSF}$ & .15 & $-.51 * * *$ & $-.65 * * *$ & $-.31 *$ & $-.35 * *$ & $.54 * * *$ & - & -.08 & .04 \\
\hline 8. S-P [g] & .03 & -.10 & -.10 & -.12 & -.14 & .21 & $.28^{*}$ & 一 & $.74 * * *$ \\
\hline 9. $\mathrm{S}-\mathrm{P}[\mathrm{b}]$ & $-.25^{*}$ & $-.34 * *$ & $-.45 * * *$ & $-.27 *$ & $-.32 *$ & $.29 *$ & $.44^{* *}$ & $.56 * * *$ & - \\
\hline 10. S-P [p] & .03 & -.13 & -.17 & -.14 & -.15 & .12 & $.26^{*}$ & $.60 * * *$ & $.57 * * *$ \\
\hline
\end{tabular}

Note. Results are for the university-aged subsample only (ages 18-23, 40 males, 51 females). Correlations for males are presented above the diagonal, and correlations for females are presented below it. Values of $p$ are one-tailed. $\mathrm{WC}=$ waist circumference, $\mathrm{BSF}=$ body shape femininity, $\mathrm{S}-\mathrm{P}[\mathrm{g}]=$ self-perceived attractiveness [general], S-P [b] = self-perceived attractiveness [body], S-P [p] = self-perceived attractiveness [percentile]. $*_{p}<.05, * * p<.01, * * * p<.001$. 